\title{
Mark-up Bancário, Conflito Distributivo e Utilização da Capacidade Produtiva: Uma Macrodinâmica Pós-Keynesiana*
}

\author{
Gilberto Tadeu Lima* \\ Antonio J. A. Meirelles ${ }^{* * *}$
}

Sumário: 1. Introdução; 2. Estrutura do modelo; 3. Comportamento do modelo no curto prazo; 4. Comportamento do modelo no longo prazo; 5 . Reprise e considerações finais.

Palavras-chave: mark-up bancário; conflito distributivo; utilização da capacidade.

Código JEL: E12; E51; E22.

Elabora-se um modelo macrodinâmico pós-keynesiano de utilização da capacidade, distribuição e inflação por conflito, no qual a oferta de moeda de crédito é endógena. A taxa nominal de juros é determinada pela aplicação de um mark-up sobre a taxa básica fixada pela autoridade monetária. Ao longo do tempo, o mark-up bancário varia com a taxa de lucro sobre o capital físico, enquanto a taxa básica varia com excessos de demanda que não são acomodáveis pela utilização da capacidade. São analisados os casos em que a demanda é suficiente ou não para gerar a plena utilização da capacidade.

It is developed a post-keynesian macrodynamic model of capacity utilization, distribution and conflict inflation, in which the supply of credit-money is endogenous. Nominal interest rate is determined by banks as a markup over the base rate, which is set by the monetary authority. Over time, banking markup varies with firms' profit rate on physical capital, while the base rate rises with any excess demand when capacity is fully utilized. The behavior of the economy is analyzed for the cases in which demand is or is not enough to ensure full capacity utilization.

\footnotetext{
*Artigo recebido em jan. 2001 e aprovado em dez. 2001. A elaboração da presente versão beneficiou-se de observações feitas por Fernando Garcia, Helder Ferreira de Mendonça, João Sicsú e pelo parecerista anônimo, valendo, entretanto, as isenções usuais. Agradecemos também o suporte do CNPq, sob a forma de bolsas de Produtividade em Pesquisa.

${ }^{* *}$ Professor do Departamento de Economia da FEA/USP. E-mail: giltadeu@usp.br

*** Professor da Faculdade de Engenharia de Alimentos da UNICAMP. E-mail: tomze@ceres.fea.unicamp.br
} 


\section{Introdução}

Este artigo desenvolve um modelo macrodinâmico pós-keynesiano de utilização da capacidade produtiva e distribuição em que a oferta de moeda é endógena. A taxa nominal de juros é determinada através da aplicação de um mark-up bancário sobre a taxa de juros básica fixada exogenamente pela autoridade monetária. Por sua vez, a taxa de inflação é determinada por um mecanismo de conflito distributivo, onde o mark-up desejado das firmas depende positivamente da taxa de juros nominal enquanto o salário real desejado pelos trabalhadores depende positivamente de seu poder de barganha salarial no mercado de trabalho. Quando a capacidade produtiva está sendo plenamente utilizada, porém, um excesso de demanda criará uma pressão adicional sobre a taxa de inflação além daquela advinda do conflito distributivo.

Ao longo do tempo, a taxa nominal de juros varia de acordo com variações em seus componentes. A taxa básica é alterada positivamente pela autoridade monetária sempre que um excesso de demanda no mercado de bens não pode ser acomodado por uma variação correspondente na utilização da capacidade produtiva, ou seja, quando esta é plena. O mark-up bancário responde negativamente a variações na lucratividade das firmas. Um aumento na taxa de lucro sobre o capital físico, ao ampliar a capacidade das firmas de servir obrigações financeiras e, com isso, reduzir seu risco percebido de inadimplência, engendra uma redução no mark-up bancário. Como o nível do preço também varia ao longo do tempo, está montado então o cenário para uma análise dinâmica baseada nas variáveis de estado salário real e taxa de juros nominal.

Em relação a seus similares pós-keynesianos — por exemplo, Dutt $(1989,1992)$ e Dutt e Amadeo (1993) — , a principal inovação do presente modelo diz respeito ao modo de incorporação da endogeneidade da oferta monetária. A exemplo daqueles modelos, assume-se que os bancos têm condições de atender plenamente a demanda por empréstimos à taxa de juros nominal vigente. No modelo que segue, os bancos podem assim proceder seja porque mantêm ativos líquidos, tais como títulos governamentais de curto prazo, em quantidade suficiente, seja porque operam com algum excesso de reservas, ou, por fim, porque podem recorrer a empréstimos da autoridade monetária. O ponto a ser destacado é que a capacidade de os bancos expandirem seus empréstimos não estará sujeita, no presente modelo, a qualquer restrição quantitativa oriunda de uma eventual insuficiência de reservas, já que a política da autoridade monetária será executada essencialmente via definição da taxa básica. ${ }^{1}$ Nesse contexto, a taxa de juros cobrada pela con-

\footnotetext{
${ }^{1}$ No Treatise on Money, Keynes (1971 [1930], p. 47) observa que os bancos "raramente
} 
cessão de empréstimos é estabelecida pela aplicação de um mark-up sobre a taxa básica de captação, de acordo com o mecanismo sugerido por Rousseas (1985). Em contraste com aqueles modelos, porém, o mark-up bancário - e, portanto, a própria taxa de concessão de empréstimos - é uma variável intertemporalmente endógena no modelo a seguir. Vale dizer, a suposição de endogeneidade da oferta monetária não se traduz aqui em uma exogeneidade plena da taxa de juros nominal, como admitido com freqüência em vários modelos pós-keynesianos, entre eles os anteriormente citados. Embora a opção pela exogeneidade da taxa de juros nominal seja justificável pela conveniência de simplificar a elaboração de modelos dinâmicos, não faz sentido, do ponto de vista conceitual, excluir a priori a possibilidade de que o mark-up bancário varie endogenamente ao longo do tempo.

Sem dúvida, a capacidade de pagamento das firmas, o receio dos bancos quanto aos efeitos de um aumento da taxa de inflação sobre a taxa de juros real e a própria capacidade dos bancos de honrar compromissos na eventualidade de inadimplência de seus devedores, normalmente influenciam a fixação da margem que os bancos aplicam sobre a taxa básica de captação. É pouco provável que os bancos sempre reajam a uma expansão na demanda por moeda de crédito somente com ajustes via quantidade, pois a expansão do crédito pode elevar seus níveis de exposição e alavancagem. De uma perspectiva mais geral, pode-se argumentar que a preferência pela liquidez dos bancos afeta a taxa na qual eles se dispõem a conceder empréstimos. $^{2}$

Por outro lado, essa opção por tratar o mark-up bancário como uma variável endógena parece compatível com as concepções expressas por diversos autores póskeynesianos, não obstante as controvérsias que cercam suas diferentes visões sobre a endogeneidade monetária, em especial aquelas referentes ao formato da curva de oferta de moeda. Por exemplo, Lavoie (1996), defensor da completa endogeneidade

ou nunca mantêm reservas ociosas em excesso ao que é sua proporção convencional ou legal". Esclarece, no entanto, que essa conclusão está sujeita ao requisito de que os bancos tenham acesso a ativos que rendam juros, cuja liquidez seja praticamente completa, ou, em suas palavras, a "ativos que rendam juros e sejam absolutamente líquidos" (p. 48). A liquidez desses ativos envolve não somente a sua imediata conversibilidade em moeda, mas também a estabilidade de seu preço, o que novamente nos remete ao aspecto básico mencionado acima: do ponto de vista do desenvolvimento do presente modelo, a hipótese central é que o acesso dos bancos a reservas que lhes permitam expandir seus empréstimos seja "restringido" apenas via preço, ou seja, por meio da taxa básica de captação de recursos, a qual é rígida no curto prazo. Agradecemos a um parecerista anônimo desta revista a indicação dos trechos acima do Treatise on Money.

${ }^{2}$ É importante observar que as variações na preferência pela liquidez também podem se refletir no prazo de maturação dos empréstimos concedidos. No entanto, como o presente modelo não incorpora de forma explícita o portfólio bancário, essa possibilidade não será considerada e o efeito daquelas variações só poderá se expressar no nível do próprio mark-up. 
da oferta monetária e da correspondente curva de oferta horizontal, afirma que os "mark-ups [bancários] podem variar bastante por razões relacionadas à preferência pela liquidez" (p. 294). Elevações da taxa de juros, provocadas, por exemplo, por uma posição não acomodatícia por parte da autoridade monetária, poderiam ser vistas como deslocamentos verticais da curva de oferta de moeda, eventualmente atenuados, ou então amplificados, por variações no mark-up bancário (idem, p. 278-281). Já Wray (1992) sugere que, a um dado grau de preferência pela liquidez, a expansão dos balancetes bancários aumenta os riscos estimados pelo emprestadores e tomadores de empréstimos, "de forma que os bancos elevam suas taxas de juros de empréstimos no varejo. Como conseqüência, a curva de oferta de moeda [seria] positivamente inclinada com relação à taxa de juros" (p. 305). A despeito dessas diferenças, porém, variações da taxa de juros nominal podem ser interpretadas analiticamente, tanto em um caso como no outro, como derivadas de variações endógenas do mark-up bancário, além obviamente de serem também oriundas de mudanças da taxa básica. ${ }^{3}$

O restante do artigo está assim organizado. A seção 2 descreve a estrutura do modelo formal. A seção 3 analisa o comportamento do modelo no curto prazo, enquanto a seção 4 faz o mesmo para o longo prazo, tanto quando a capacidade produtiva está sendo plenamente utilizada como quando essa utilização é apenas parcial. Ainda na seção 4, desenvolve-se uma análise qualitativa de possíveis configurações sistêmicas marcadas por equilíbrios dinâmicos duplos para as variáveis endógenas. Um reprise dos principais resultados derivados ao longo do artigo e breves considerações finais ocupam a última seção.

\section{Estrutura do Modelo}

A economia é fechada e sem atividades fiscais por parte do governo, produzindo um único bem utilizável tanto para consumo como para investimento. São

\footnotetext{
${ }^{3}$ No caso das concepções de Moore (1988), no entanto, a compatibilidade com o presente modelo parece menos provável. Ele sugere que o mark-up bancário é "relativamente estável", o que é necessário para fundamentar sua conclusão de que a autoridade monetária exerce um substancial controle sobre as taxas de juros de curto prazo. Esta constatação pode ser verificada nos seguintes trechos: "a presente análise sugere que as taxas de curto prazo são mais corretamente vistas simplesmente como um mark-up relativamente estável sobre a taxa dos fundos federais, a qual é exogenamente administrada pelas autoridades monetárias" (p. 283); "[a] taxa de juros de curto prazo é o centro de gravitação em torno do qual giram as taxas de todos os demais ativos, financeiros e não-financeiros. E ao longo de uma ampla faixa, as taxas de juros de curto prazo são administradas exogenamente pelos bancos centrais" (p. 289). Para uma análise detalhada das diversas concepções pós-keynesianas acerca da endogeneidade monetária, vide Meirelles (1995, 1998).
} 
empregados somente dois fatores em sua produção, capital e trabalho, combinados por meio de uma tecnologia de coeficientes fixos:

$$
X=\min \left[K u_{K}, L / a\right]
$$

onde $X$ é o nível de produto, $K$ é o estoque de capital, $L$ é o nível de emprego, $u_{K}$ é a relação produto potencial-capital, enquanto $a$ é a relação trabalho-produto. A hipótese de coeficientes fixos pode ser justificada com base numa independência da escolha de técnicas quanto ao preço relativo dos fatores ou numa rigidez tecnológica na substituição entre eles.

A atividade produtiva é realizada por firmas oligopolistas e, portanto, formadoras de preço. Elas produzem (e contratam mão-de-obra) de acordo com a demanda efetiva, caso seja esta insuficiente para garantir a plena utilização da capacidade, $u_{K}$, ou então, do contrário, a este nível máximo. Portanto, as firmas podem operar com excesso de capacidade produtiva em termos de capital ${ }^{4}$, enquanto o nível de emprego é determinado pela produção efetiva:

$$
L=a X
$$

implicando que nenhum excesso de mão-de-obra é empregado, dado inexistirem contratos de trabalho de longa duração. As firmas também respondem pela acumulação de capital físico, sendo que seu investimento desejado é descrito pela seguinte equação:

$$
g^{d}=\alpha_{0}+\alpha_{1} r-\alpha_{2}(i-\hat{P})
$$

onde $\alpha_{i}$ são parâmetros positivos, $g^{d}$ é a acumulação desejada das firmas como fração do estoque de capital, $r$ é a taxa de lucro sobre o capital físico, definida como o fluxo monetário de lucros, $R$, dividido pelo valor nominal do estoque de capital, $i$ é a taxa nominal de juros e $\hat{P}$ é a taxa de inflação. Como Rowthorn (1981) e Dutt (1990), seguimos Kalecki (1971) na suposição de que o investimento desejado das firmas depende positivamente da taxa de lucro, porquanto esta não somente representa um indicador dos ganhos futuros esperados, mas, inclusive, fornece recursos internos - e facilita a obtenção de recursos externos — para a

\footnotetext{
${ }^{4}$ Segundo Steindl (1952), as firmas oligopolistas operam com uma margem desejada de capacidade ociosa para estarem prontas para aumentos repentinos na demanda. Por um lado, a indivisibilidade e a durabilidade da planta e dos equipamentos impede que a capacidade produtiva se expanda pari passu ao crescimento do mercado. Por outro, isso funciona como uma barreira à entrada: a existência de um excesso de capacidade permite confrontar firmas recém-ingressantes por meio de um súbita elevação da oferta que reduza os preços.
} 
acumulação de capital. Quanto ao efeito do juro real, medindo o custo do capital financeiro, seguimos Dutt (1994).

A economia ora modelada é habitada por duas classes, capitalistas e trabalhadores. Seguindo a tradição pós-keynesiana inaugurada por Kalecki (1971), assumimos que essas classes adotam diferentes comportamentos de consumo. Os trabalhadores ofertam mão-de-obra e recebem apenas salários, os quais são totalmente gastos em consumo. O conjunto dos capitalistas, incluindo os produtivos e os financeiros, recebem sob a forma de lucros todo o excedente sobre os salários, poupando, respectivamente, as frações $s_{p}$ e $s_{f}$ de sua parcela dos lucros, sendo assumido que $s_{p}=s_{f}=s$. Assim, a divisão funcional da renda é dada por:

$$
X=(W / P) L+R
$$

onde $W$ é o salário nominal e $P$ é o nível do preço. Sendo assim, os lucros dos capitalistas financeiros representam uma dedução do fluxo de lucros gerado pelo estoque de capital físico, numa proporção dada pelo estoque de dívida dos capitalistas produtivos junto aos capitalistas financeiros e pela taxa de juros. Normalizando a eq. (4) pelo estoque de capital e definindo $V$ como sendo o salário real, a taxa de lucro sobre o capital físico pode ser expressa como:

$$
r=(1-V a) u
$$

onde $(1-V a)$ é a participação dos lucros na renda e $u=X / K$ é o grau de utilização da capacidade produtiva. De fato, como assumimos a constância da proporcionalidade entre o produto potencial e o estoque de capital, a relação produto-capital pode servir como indicador do grau de utilização da capacidade. ${ }^{5}$

O nível do preço está dado num ponto do tempo, podendo crescer ao longo dele por duas razões. A primeira é um eventual excesso do mark-up desejado das firmas sobre o mark-up efetivo, enquanto que a segunda, operante somente sob condições de plena utilização da capacidade, é um excesso de demanda no mercado de bens. Formalmente:

\footnotetext{
${ }^{5}$ Para efeito de simplificação e focalização, o presente modelo também ignora variações na produtividade do trabalho. Para dois modelos dinâmicos pós-keynesianos em que inovações tecnológicas poupadoras de trabalho ocorrem a taxas endógenas, porém o lado monetário da economia não é formalizado, vide Lima $(1999,2000)$. No primeiro, a taxa de inovação tecnológica varia não-linearmente com a parcela salarial na renda. No segundo, com um espírito neo-schumpeteriano, a taxa de inovação depende não-linearmente da concentração de mercado. Em ambos, a não-linearidade envolvida gera possíveis equilíbrios dinâmicos múltiplos e trajetórias cíclicas para as variáveis endógenas.
} 


$$
\hat{P}=\theta_{1}\left(V-V_{f}\right)+\theta_{2}\left(g^{d}-g\right)
$$

onde $\hat{P}$ é a taxa proporcional de variação do preço, $(d P / d t)(1 / P), g$ é a poupança agregada como fração do estoque de capital, conforme a eq. (14) abaixo, e $\theta_{i}>0$ são parâmetros. Abaixo da plena utilização da capacidade, a inflação resulta de um conflito distributivo, sendo o mecanismo que compatibiliza ex-post demandas pela renda que sejam incompatíveis ex-ante. Quando a capacidade está sendo plenamente utilizada, a evolução da taxa de inflação passa a ser governada também por excessos de demanda, concebidos aqui como oriundos de excessos da acumulação desejada sobre a acumulação efetiva. E como assumimos que esses excessos de demanda ocorrem a um dado nível do preço, o racionamento correspondente recai então sobre o investimento desejado das firmas e não sobre o consumo.

O mark-up sobre os custos primários, à maneira de Kalecki (1971), é dado por:

$$
P=(1+z) W a
$$

onde $z$ é o mark-up. ${ }^{6}$

Dada a produtividade do trabalho, o mark-up efetivo e o salário real estão inversamente relacionados, de maneira que o hiato entre o mark-up desejado e o efetivo pode ser medido pelo hiato entre o salário real efetivo e aquele correspondente ao mark-up desejado, conforme a eq. (6). O mark-up desejado das firmas varia positivamente com o juro nominal, dado que sua renda de mark-up deve cobrir inclusive custos financeiros. Assim:

$$
V_{f}=\varphi_{0}-\varphi_{1} i
$$

onde $\varphi_{i}$ são parâmetros positivos. Por sua vez, a taxa nominal de juros, à forma de Rousseas (1985), é determinada pelo setor bancário a partir da aplicação de

\footnotetext{
${ }^{6}$ Um padrão de formação de preços dessa natureza pode ser racionalizado como adequado em situações em que as condições de demanda de mercado são inerentemente incertas, impossibilitando assim um cálculo preciso de maximização de lucros. Não obstante, o mark-up pode ser derivado a partir de microfundamentos explícitos de maximização, como, a propósito, feito inicialmente - embora abandonado posteriormente — pelo próprio Kalecki (1939-40). Em Cowling (1982, cap. 2), por exemplo, o mark-up da firma oligopolista depende da elasticidade da demanda, de suas conjecturas sobre as reações dos competidores às suas decisões de produção e de uma medida de concentração industrial.
} 
um mark-up, $h>1$, sobre a taxa básica de juros, $i^{*}$, que é fixada pela autoridade monetária: ${ }^{7}$

$$
i=h i^{*}
$$

Portanto, o fato de o bancos terem condições de satisfazer plenamente a demanda por empréstimos à taxa de juros nominal vigente, seja por operarem com excesso de reservas ou por poderem recorrer a empréstimos da autoridade monetária, não significa que esta não possa influenciar o processo endógeno de criação de moeda de crédito em que se baseia o presente modelo. Aqui, entretanto, essa influência se dá em nível de preço, através da dosagem da taxa de juros básica, e não de restrições quantitativas. Da mesma forma, a assumida endogeneidade da moeda de crédito não implica na impossibilidade de os próprios bancos influenciarem o acesso efetivo a ela. No modelo deste artigo, entretanto, essa influência é exercida em nível de restrições de acesso ao crédito via preço, não via quantidade.

Os níveis da taxa básica, do mark-up bancário e, assim, da taxa de juros nominal, estão pré-determinados num momento do tempo. O mark-up bancário, porém, varia ao longo do tempo de maneira endógena, de acordo com a evolução da taxa de lucro sobre o capital físico:

$$
\hat{h}=\beta_{0}-\beta_{1} r
$$

onde $\hat{h}$ é taxa proporcional de variação do mark-up bancário, $(d h / d t)(1 / h)$, enquanto que $\beta_{0}$ é um termo autônomo de sinal positivo ou negativo e $\beta_{1}$ é um parâmetro positivo. O termo autônomo reflete variações exógenas no mark-up bancário derivadas de fatores tais como características internas dos agentes bancários, níveis de taxação explícita e implícita, estrutura competitiva do sistema bancário e arcabouço legal de regulação e supervisão bancária. Por sua vez, um aumento na taxa de lucro sobre o capital físico, ao elevar a capacidade potencial das firmas de servir suas obrigações financeiras e, portanto, reduzir seu risco percebido de inadimplência, induzirá uma redução no mark-up bancário. ${ }^{8}$

Em termos da influência da inadimplência sobre o nível dos spreads bancários, vale mencionar o estudo realizado pelo Banco Central do Brasil (1999), utilizando

\footnotetext{
${ }^{7}$ Baseado na teoria kaleckiana da fixação de preços em mercados de bens oligopolizados, da qual fazemos uso neste artigo, conforme a eq. (7), Rousseas (1985) sugere que o preço dos empréstimos bancários é igualmente determinado por uma regra de mark-up. Especificamente, ele seria fixado pela aplicação de um mark-up sobre o custo de captação dos fundos para realização desses empréstimos, com os custos fixos e de mão-de-obra estando incluídos nessa margem.

${ }^{8}$ Uma relação positiva entre risco de inadimplência e margem bancária é derivada, por exemplo, em Wong (1997) e Angbazo (1997), em ambos os casos dotando-a de microfundamentos explícitos de maximização.
} 
dados de uma amostra de dezessete bancos privados nacionais para o trimestre Maio-Julho daquele ano. A decomposição contábil feita nesse estudo revelou então que a inadimplência representava o principal componente dos spreads bancários em geral, respondendo, em média, por $35 \%$ do valor destes - com percentuais de $28 \%$ e $40 \%$, em média, para empréstimos aos tomadores pessoa física e pessoa jurídica, respectivamente.

Como veremos na seção seguinte, a utilização da capacidade e a taxa de lucro sobre o capital físico movem-se na mesma direção quando a primeira encontra-se abaixo de seu nível pleno, de maneira que a segunda pode ser vista como um indicador do nível de atividade. Algumas evidências empíricas para essa hipótese de mark-up bancário anti-cíclico podem ser buscadas em Aronovich (1994), onde são utilizados dados nacionais entre o início de 1986 e o final de 1992. Nele, o spread da taxa de capital de giro caracterizou-se por um sinal negativo e estatisticamente significante do coeficiente relativo ao grau de utilização da capacidade. Quanto ao spread das operações de desconto de duplicata, porém, esse coeficiente mostrou-se estatisticamente não-significativo. ${ }^{9}$ Por sua vez, o estudo de Angbazo (1997) sobre o sistema bancário norte-americano detectou que a participação dos empréstimos inadimplentes nos empréstimos totais era uma variável explicativa significante dos spreads bancários, enquanto Saunders e Schumacher (2000), com base em dados para seis países europeus e os Estados Unidos nos anos 1988-1995, detectaram um impacto positivo significativo do risco de crédito percebido sobre as margens bancárias. ${ }^{10}$

\footnotetext{
${ }^{9}$ Este estudo de Aronovich (1994) revelou também que outro determinante importante do mark-up bancário é a taxa de inflação. Nele, o spread das operações de desconto de duplicata caracterizou-se por um sinal positivo elevado e estatisticamente significante do coeficiente relativo à taxa de inflação. Quanto ao spread da taxa de capital de giro, uma relação positiva com a taxa de inflação também foi detectada, embora estatisticamente não-significativa. Por sua vez, o estudo recente de Demirgüç-Kunt e Huizinga (1999), utilizando dados para oitenta países no período 1988-1995, evidenciou a influência positiva da taxa de inflação sobre o mark-up bancário. No presente modelo, porém, focalizamos a atenção apenas na influência da taxa de lucro sobre o capital físico. Para um modelo semelhante, onde o mark-up bancário varia positivamente com a taxa de inflação e negativamente com a utilização da capacidade produtiva, vide Meirelles (2001b). Neste último, porém, a taxa de juros básica varia exogenamente e apenas a situação de ocupação da capacidade abaixo da plena é considerada, entre outras diferenças.

${ }^{10}$ Nesse estudo, Saunders e Schumacher (2000) detectaram ainda que componentes regulatórios - restrições de taxas de juros sobre depósitos, requisitos de reservas e razões capital-ativo exercem um impacto significativo sobre as margens bancárias, enquanto que um maior grau de segmentação do sistema bancário, por atividade e geograficamente, ao implicar em maior poder de monopólio dos bancos existentes, finda resultando em margens mais elevadas. Além disso, os resultados desse estudo sugerem um importante trade-off em nível de regulação entre a asseguração da solvência bancária — razões capital-ativo elevadas — e a redução do custo dos
} 
A taxa de juros básica, por sua vez, é alterada positivamente pela autoridade monetária sempre que um excesso de demanda no mercado de bens não for acomodável por uma variação na utilização da capacidade produtiva, ou seja, quando $u=u_{k}$. Formalmente:

$$
\hat{i}^{*}=\phi\left(g^{d}-g\right)
$$

onde $\hat{i}$ é taxa proporcional de variação da taxa de juros básica, $\left(d i^{*} / d t\right) /\left(1 / i^{*}\right)$, enquanto que $\phi$ é um parâmetro positivo.

O salário nominal também está dado num ponto do tempo, porém crescerá ao longo dele de acordo com o hiato entre o salário real desejado pelos trabalhadores, $V_{w}$, e o salário real efetivo. Formalmente:

$$
\hat{W}=\mu\left(V_{u}-V\right)
$$

onde $\hat{W}$ é a taxa proporcional de variação do salário nominal, $(d W / d t)(1 / W)$, e $\mu>0$ é um parâmetro. Portanto, seguimos Keynes (1936) na suposição de que a barganha salarial ocorre em termos nominais. ${ }^{11}$ Por sua vez, o salário real desejado pelos trabalhadores depende de seu poder de barganha no mercado de trabalho. Um aumento na taxa de emprego eleva o poder de barganha dos trabalhadores e, portanto, os leva a desejar um salário real mais alto. Dado que a tecnologia é de coeficientes fixos, além de estarmos abstraindo de variações na produtividade do trabalho, variações na taxa de emprego podem ser aproximadas por variações no grau de utilização da capacidade. Formalmente:

$$
V_{w}=\epsilon_{0}+\epsilon_{1} u
$$

onde $\epsilon_{i}$ são parâmetros positivos.

Sob condições de excesso de capacidade produtiva em termos de capital físico, as firmas produzirão de acordo com a demanda, de maneira que a equalização $e x$ post entre a acumulação desejada e a poupança será gerada, conforme o princípio da demanda efetiva, por intermédio de variações no grau de utilização da capacidade. Como proporção do estoque de capital, a poupança é dada por:

\footnotetext{
serviços financeiros para os consumidores - margens bancárias baixas.

${ }^{11}$ Uma das razões que levou Keynes (1936) a rejeitar o segundo postulado clássico é que este supõe a fixação do salário real pela barganha salarial. Para ele, postular que existe uma tendência à igualação entre o salário real e a desutilidade marginal do trabalho equivale a assumir, erroneamente, que os trabalhadores estão em condições de decidir o salário real pelo qual trabalham. Sobre a economia do emprego de Keynes, vide Lima (1992).
} 


$$
g=s r
$$

algo que se segue diretamente das suposições de os trabalhadores não pouparem e o conjunto dos capitalistas poupar uma certa fração, $s$, de sua parcela na renda, conforme argumentado no parágrafo que antecede a eq. (4).

\section{Comportamento do Modelo no Curto Prazo}

No curto prazo, o estoque de capital, $K$, o juro nominal, $i$, a relação trabalhoproduto, $a$, o nível de preço, $P$, e o salário nominal, $W$, estão dados. Consideremos as possibilidades em termos de utilização da capacidade.

\subsection{Situação de excesso de capacidade}

A existência de capacidade ociosa permite que as firmas concretizem seus planos de acumulação, com a utilização da capacidade se ajustando para eliminar qualquer excesso de demanda ou de oferta. No equilíbrio de curto prazo, portanto, a necessária igualdade entre poupança e investimento, $g=g^{d}$, é promovida então por variações no grau de utilização da capacidade produtiva. Utilizando as eqs. (3), (5), (6), (8) e (14), podemos obter a solução de equilíbrio de curto prazo de $u$, dados $V, i$ e os parâmetros do modelo:

$$
u^{*}=\frac{\alpha_{0}+\alpha_{2} \theta_{1}\left(V-\varphi_{0}\right)-\alpha_{2} i\left(1-\theta_{1} \varphi_{1}\right)}{\left(s-\alpha_{1}\right)(1-V a)}
$$

Em termos de estabilidade, assumimos o mecanismo de ajuste keynesiano de acordo com o qual a utilização da capacidade varia positivamente com qualquer excesso de demanda no mercado de bens. Portanto, o valor de equilíbrio de $u$ será estável caso o denominador da eq. (15) seja positivo, vale dizer, caso a poupança seja mais sensível que o investimento a variações na utilização da capacidade. Dado ser necessário assumir valores positivos para o salário real e para a participação dos lucros na renda, a satisfação da condição de estabilidade de $u^{*}$ requer $s>\alpha_{1} \cdot{ }^{12}$

Para garantir que $u^{*}$ alcance somente valores positivos, assumimos ainda que o numerador da eq. (15) é positivo. ${ }^{13}$

Dada a taxa de juros nominal, a resposta de $u^{*}$ a variações no salário real é dada por:

\footnotetext{
${ }^{12}$ Formalmente, o referido mecanismo de ajuste é dado por $\dot{u}=d u / d t=\left[g^{d}-g\right]$, com que a estabilidade do equilíbrio de curto prazo da utilização da capacidade requer $d \dot{u} / d u<0$.

${ }^{13} \mathrm{~A}$ inequação correspondente é $i<\left[\alpha_{0}-\alpha_{2} \theta_{1} \varphi_{0} / \alpha_{2}\left(1-\theta_{1} \varphi_{1}\right)\right]+\left[\theta_{1} V /\left(1-\theta_{1} \varphi_{1}\right)\right]$.
} 


$$
\partial u^{*} / \partial V=\frac{\alpha_{2} \theta_{1}+a u^{*}\left(s-\alpha_{1}\right)}{D}
$$

onde $D$ é o denominador de $u^{*}$. Uma vez que a satisfação da condição de estabilidade de $u^{*}$ requer $s>\alpha_{1}$, um aumento no salário real provoca uma variação na mesma direção no valor de equilíbrio de curto prazo de $u$. Um aumento na taxa de salário real, dado o coeficiente trabalho-produto, transfere renda dos capitalistas para os trabalhadores e, como a propensão a consumir destes é superior à daqueles, eleva o grau de utilização da capacidade. Além disso, um aumento no salário real, dado o salário real implicado pelo mark-up desejado das firmas, eleva a taxa de inflação e, dado o juro nominal, reduz o juro real. E como o nível de atividade é guiado pela demanda quando a economia opera com capacidade ociosa, essa queda no juro real eleva a acumulação desejada das firmas e o grau de utilização da capacidade.

Dado o salário real, a resposta de $u^{*}$ a variações no juro nominal é dada por:

$$
\partial u^{*} / \partial i=\frac{-\alpha_{2}\left(1-\theta_{1} \varphi_{1}\right)}{D}
$$

onde, como anteriormente, $D$ é o denominador de $u^{*}$. Portanto, o impacto de uma variação na taxa de juros nominal sobre o equilíbrio de curto prazo do grau de utilização da capacidade depende do sinal do termo entre parênteses no numerador da expressão acima. Como mostra a eq. (8), um aumento na taxa de juros nominal eleva o mark-up desejado das firmas, o que, dado o salário real efetivo, eleva a taxa proporcional de variação do preço, conforme a eq. (6). Sendo assim, dado o salário real efetivo, o termo entre parênteses no numerador da expressão acima mede o impacto de uma variação na taxa de juros nominal sobre a taxa de juros real:

$$
\partial(i-\hat{P}) / \partial i=\left(1-\theta_{1} \phi_{1}\right)
$$

Portanto, um sinal positivo para a expressão acima implica que um aumento nominal na taxa de juros se traduz num aumento no valor real desta variável e, como mostra a eq. (3), reduz o investimento desejado das firmas. Nesse caso, portanto, um aumento na taxa de juros nominal provoca uma queda no equilíbrio de curto prazo de $u$. Na análise dinâmica a ser desenvolvida na seção seguinte, assumiremos que os sinais das expressões (18) e (17) são, respectivamente, positivo e negativo.

Por sua vez, o valor de equilíbrio de curto prazo da taxa de lucro gerada pelo capital físico, $r^{*}$, pode ser obtido por meio da substituição, na eq. (5), do valor de equilíbrio de $u^{*}$ : 


$$
r^{*}=\frac{\left.\alpha_{0}+\alpha_{2} \theta_{1}\left(V-\varphi_{0}\right)-\alpha_{2} i\left(1-\theta_{1} \varphi_{1}\right)\right]}{\left(s-\alpha_{1}\right)}
$$

Dada a taxa de juros nominal, a resposta de $r^{*}$ a variações no salário real é dada por:

$$
\partial r^{*} / \partial V=\frac{\alpha_{2} \theta_{1}}{\left(s-\alpha_{1}\right)}
$$

Como a satisfação da condição de estabilidade de $u^{*}$ requer $s>\alpha_{1}$, um aumento no salário real provoca uma variação na mesma direção no valor de equilíbrio de curto prazo da taxa de lucro. Dados o equilíbrio da utilização da capacidade e o coeficiente trabalho-produto, um aumento no salário real real reduz a participação dos lucros na renda e, conforme a eq. (5), reduz a taxa de lucro. Contudo, esse aumento no salário real, conforme a eq. (16), eleva mais que proporcionalmente a utilização da capacidade, elevando assim a taxa de lucro.

Por seu turno, dado o salário real, a resposta imediata de $r^{*}$ a variações na taxa de juros nominal é dada por:

$$
\partial r^{*} / \partial i=\frac{-\alpha_{2}\left(1-\theta_{1} \varphi_{1}\right)}{\left(s-\alpha_{1}\right)}
$$

Portanto, o impacto de uma variação na taxa de juros nominal sobre o equilíbrio de curto prazo da taxa de lucro depende, como no caso de seu impacto sobre $u^{*}$, de seu efeito de curto prazo sobre a taxa de juros real, o qual é captado pela expressão (18). Como assumimos um sinal positivo para essa expressão, um aumento na taxa de juros nominal reduzirá a taxa de lucro sobre o capital físico.

\subsection{Situação de plena utilização da capacidade}

Como observado na sub-seção anterior, um aumento (redução) no salário real (juro nominal) provoca uma elevação na utilização da capacidade. Assim, é possível localizar no espaço $(V, i)$ uma região em que o grau de utilização atinge a plenitude, com a linha divisória entre ela e aquela correspondente a $u<u_{K}$ sendo de inclinação e intercepto positivos. ${ }^{14}$

\footnotetext{
${ }^{14}$ Para obtê-la, basta substituir $u_{K}$ na expressão para $u^{*}$ e rearranjar. Retomando as condições assumidas para a positividade e estabilidade de $u^{*}$ e o sinal da eq. (18), basta assumir $\alpha_{0}>$ $\left(s-\alpha_{1}\right) u_{K}+\alpha_{2} \theta_{1} \varphi_{0}$ para garantir que as retas que descrevem as condições para a positividade do numerador de $u^{*}$ e para $u=u_{K}$ tenham inclinação e intercepto positivos, com o intercepto da primeira sendo maior. Mas como a inclinação da segunda é maior, seu cruzamento ocorre em
} 
Na região de plena utilização da capacidade, caso ocorra um excesso de demanda dado por $g^{d}>g$, as firmas não poderão realizar sua acumulação desejada, conforme elaboramos na sequência da eq. (6). Quando $u=u_{K}$, portanto, a taxa de lucro gerada pela acumulação de capital físico será dada, conforme a eq. (5), por:

$$
r=(1-V a) u_{K}
$$

Para calcularmos a taxa de acumulação efetiva, basta então substituirmos a eq. (22) na eq. (14), com que obtemos:

$$
g=s(1-V a) u_{K}
$$

Para obtermos o valor de equilíbrio de curto prazo da taxa de inflação, por sua vez, basta utilizarmos as eqs. (3), (6), (8), (22) e (23), com as substituições devidas gerando então:

$$
\hat{P}=\theta_{1}^{\prime}\left(V-\phi_{0}\right)+\theta_{2}^{\prime}\left[\alpha_{0}-\left(s-a l p h a_{1}\right)(1-V a) u_{k}\right]+\theta_{1}^{\prime \prime} i
$$

onde:

$\theta_{1}^{\prime}=\theta_{1} /\left(1-\theta_{2} \alpha_{2}\right)$

$\theta_{2}^{\prime}=\theta_{2} /\left(1-\theta_{2} \alpha_{2}\right)$

$\theta_{1}^{\prime \prime}=\left(\theta_{1} \varphi_{1}-\theta_{2} \alpha_{2}\right) /\left(1-\theta_{2} \alpha_{2}\right)$.

Quando a plena ocupação da capacidade é alcançada, uma elevação (queda) no salário real (juro nominal) não provocará qualquer alteração no valor de equilíbrio de curto prazo do grau de utilização da capacidade. No caso do equilíbrio de curto prazo da taxa de lucro sobre o capital físico, contudo, a eq. (22) mostra que uma dada variação no salário real, ao provocar uma variação na participação dos lucros na renda, resulta numa variação na direção oposta na taxa de lucro, uma vez que o grau de utilização da capacidade deixou de desempenhar o papel acomodatício da situação de capacidade ociosa. No tocante ao impacto de uma variação na taxa nominal de juros sobre o equilíbrio de curto prazo da taxa de lucro, a eq. (22) mostra que ele é nulo, como consequência da invariabilidade da utilização da capacidade.

Por outro lado, a eq. (24) mostra que variações no salário real ou nos juros nominais provocarão variações na taxa de inflação. Um aumento no salário real,

$\overline{V=(1 / a) \text {, o que viola a condição de positividade da parcela dos lucros na renda. Portanto, a }}$ inequação acima garante a devida delimitação do sub-espaço de validade de $(V, i)$. 
por exemplo, tende a elevar o hiato entre o salário real efetivo e aquele correspondente ao mark-up desejado das firmas (primeiro termo do lado direito da eq. (24)) e a intensificar o excesso de demanda (segundo termo, lembrando que os trabalhadores têm uma maior propensão a consumir), resultando numa variação na taxa de inflação proporcional aos valores de $\theta_{1}^{\prime}$ e $\theta_{2}^{\prime}$. Uma vez que a taxa de inflação aparece recursivamente na função acumulação desejada contida em sua própria expressão, as combinações $\theta_{1}^{\prime}$ e $\theta_{2}^{\prime}$ indicam a proporção em que as tendências descritas acima se traduzem em uma elevação na taxa de inflação. $\mathrm{Na}$ sequência, portanto, assumiremos que essas combinações são positivas, pois sua negatividade significaria uma resultante deflacionária para os vários efeitos de um aumento no salário real descritos acima, contrariando a própria lógica subjacente à especificação da equação da taxa de inflação — ou seja, assumiremos $\theta_{2} \alpha_{2}<1$.

No caso de uma aumento nos juros nominais, por sua vez, esta última condição não é suficiente para definir a direção de seu impacto sobre a taxa de inflação quando a capacidade instalada está sendo plenamente utilizada. Assumimos anteriormente que uma variação na taxa de juros nominal provoca uma variação na mesma direção em seu valor real $\left(\theta_{1} \varphi_{1}<1\right)$, de maneira que o sinal da combinação paramétrica $\theta_{1}^{\prime \prime}$ será o mesmo que o de seu numerador. Um dado aumento nos juros nominais, ao elevar o mark-up desejado das firmas, aumenta a divergência entre o salário real efetivo e o implicado por aquele mark-up desejado, criando uma pressão altista sobre a taxa de inflação (primeiro termo do numerador de $\theta_{1}^{\prime \prime}$ ). Ademais, esse aumento nos juros nominais reduz diretamente a acumulação desejada, causando uma pressão baixista sobre a taxa de inflação (segundo termo do numerador de $\theta_{1}^{\prime \prime}$ ). Por fim, a taxa de inflação aparece recursivamente na função acumulação desejada participante de sua própria expressão (denominador de $\theta_{1}^{\prime \prime}$ ). Sendo assim, um aumento na taxa nominal de juros eleverá (reduzirá) a taxa de inflação quando $\theta_{1} \varphi_{1}>\theta_{2} \alpha_{2}\left(\theta_{1} \varphi_{1}<\theta_{2} \alpha_{2}\right)$. Na análise dinâmica desenvolvida na seção seguinte, consideraremos estas duas possibilidades.

\section{Comportamento do Modelo no Longo Prazo}

Para a análise de longo prazo, assumimos que os valores de equilíbrio de curto prazo das variáveis endógenas $u$ e $r$ são sempre alcançados. A economia evolui temporalmente devido a variações no estoque de capital, no juro nominal, no preço e no salário nominal. Uma forma de acompanhar a dinâmica do sistema é examinar o comportamento de duas variáveis de estado de curto prazo, a saber, o salário real e o juro nominal. 
Dada a definição dessas variáveis, temos o seguinte sistema autônomo de equações diferenciais:

$$
\begin{gathered}
\hat{V}=\hat{W}-\hat{P} \\
\hat{i}=\hat{h}+\hat{i}^{*}
\end{gathered}
$$

O exame do comportamento dinâmico da economia requer que sejam consideradas as duas possibilidades quanto ao seu grau de utilização da capacidade, ou seja, $u \leq u_{K}$.

\subsection{Situação de excesso de capacidade}

Considerando-se que $g^{d}=g$, as devidas substituições nas eqs. (25) e (26) geram:

$$
\begin{gathered}
\hat{V}=\mu\left(\epsilon_{0}+\epsilon_{1} u-V\right)-\theta_{1}\left(V-\varphi_{0}+\varphi_{1} i\right) \\
\hat{i}=\beta_{0}-\beta_{1} r
\end{gathered}
$$

onde $u$ e $r$ são dados pelas eqs. (15) e (19), respectivamente.

A matriz Jacobiana associada a esse sistema dinâmico é a seguinte:

$$
\begin{gathered}
J_{11}=\partial \hat{V} / \partial V=\mu\left(\epsilon_{1} u_{v}^{*}-1\right) \theta_{1} \\
J_{12}=\partial \hat{V} / \partial i=\mu \epsilon_{1} u_{i}^{*}-\theta_{1} \varphi_{1}<0 \\
J_{21}=\partial \hat{i} / \partial V=-\beta_{1} r_{v}^{*}<0 \\
J_{22}=\partial \hat{i} / \partial i=-\beta_{1} r_{i}^{*}>0
\end{gathered}
$$


Conforme a eq. (29), um aumento no salário real, ao elevar a utilização da capacidade, aumenta o salário real desejado pelos trabalhadores e, caso isso ocorra numa proporção superior ao aumento inicial em seu próprio nível, eleva a taxa de variação proporcional do salário nominal. Contudo, esse mesmo aumento no salário real eleva o hiato entre seu valor efetivo e aquele relativo ao mark-up desejado das firmas e, em conseqüência, eleva a taxa de variação do preço. Assim, o sinal dessa derivada depende do impacto relativo desses efeitos.

Como a expressão (18) é positiva, a eq. (30) mostra que um aumento na taxa de juros nominal, ao reduzir a utilização da capacidade produtiva, reduz o salário real desejado pelos trabalhadores e, com isso, reduz a taxa de variação proporcional do salário nominal. Além disso, esse aumento na taxa de juros nominal, ao elevar o mark-up desejado das firmas, eleva a taxa de variação proporcional do nível do preço. Sendo assim, o sinal dessa derivada parcial é negativo. Por seu turno, a eq. (31) mostra que um aumento no salário real, ao acarretar uma elevação na taxa de lucro sobre o capital físico, reduz o mark-up bancário e, com isso, reduz a taxa de variação proporcional da taxa de juros nominal. Finalmente, a eq. (32) mostra que um aumento no juro nominal, ao reduzir a taxa de lucro sobre o capital físico, eleva o mark-up dos bancos e, por conseguinte, eleva a taxa de variação proporcional da taxa de juros nominal.

Temos agora todos os elementos para uma análise qualitativa, baseada em diagramas de fase, das propriedades de estabilidade (local) do sistema. Analisemos inicialmente o caso em que $J_{11}$ é negativo, ou seja, um certo aumento no salário real eleva a taxa de variação proporcional do salário nominal numa proporção inferior ao aumento simultâneo por ele gerado na taxa de variação proporcional do nível do preço. Com isso, a solução de equilíbrio será um ponto de sela, dado que o determinante da Jacobiana é negativo, embora o sinal de seu traço seja ambíguo.

A figura 1 ilustra essa situação de instabilidade. A inclinação da isolinha $\hat{V}=0$, dada por $-\left(J_{11} / J_{12}\right)$, é negativa. Uma vez que o sinal de $\partial \hat{V} / \partial i$ é negativo, $\hat{V}$ cai conforme $i$ cresce, de maneira que seu sinal é positivo (negativo) à esquerda (direita) da correspondente isolinha, o que explica a direção das setas horizontais. Por sua vez, a inclinação da isolinha $\hat{i}=0$, dada por $-\left(J_{21} / J_{22}\right)$, é positiva. Como o sinal de $\partial \hat{i} / \partial V$ é negativo, $\hat{i}$ cai conforme $V$ sobe, seu sinal sendo positivo (negativo) à esquerda (direita) da isolinha correspondente, o que explica a direção das setas verticais. Sendo assim, o equilíbrio de longo prazo, $E_{1}$, é um ponto de sela, com a separatriz correspondente apresentando uma inclinação positiva. 
Gilberto Tadeu Lima, Antonio J. A. Meirelles

Figura 1

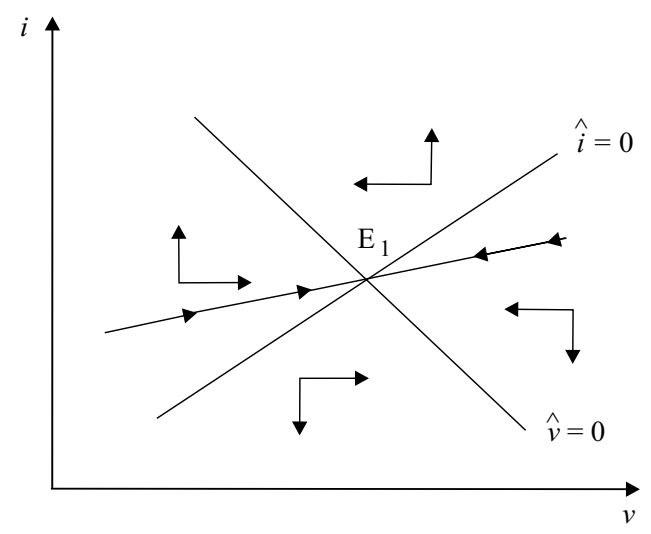

Analisemos agora a situação em que $J_{11}$ é positivo, significando que um determinado aumento no salário real eleva a taxa de variação proporcional do salário nominal numa proporção superior ao aumento simultâneo por ele gerado na taxa de variação proporcional do nível do preço. Nesse caso, o traço da Jacobiana é positivo, violando a condição necessária para a estabilidade da solução de equilíbrio. Sendo assim, caso seu determinante seja negativo (positivo), o equilíbrio será então do tipo ponto de sela (instável). A figura 2 ilustra a situação em que o referido determinante é negativo, implicando que o valor absoluto da inclinação da isolinha $\hat{i}=0$ é maior que o da isolinha $\hat{V}=0$, algo que se segue diretamente de suas expressões algébricas. A inclinação da isolinha $\hat{V}=0$, dada por $-\left(J_{11} / J_{12}\right)$, é positiva. Uma vez que o sinal de $\partial \hat{V} / \partial i$ é negativo, $\hat{V}$ cai conforme $i$ cresce, de maneira que seu sinal é positivo (negativo) à direita (esquerda) da correspondente isolinha, o que explica a direção das setas horizontais. A inclinação da isolinha $\hat{i}=0$, dada por $-\left(J_{21} / J_{22}\right)$, é igualmente positiva. Como o sinal de $\partial \hat{i} / \partial V$ é negativo, $\hat{i}$ cai conforme $V$ sobe, de maneira que seu sinal é positivo (negativo) à esquerda (direita) da isolinha correspondente, daí a direção das setas verticais. Sendo assim, o equilíbrio de longo prazo, $E_{1}$, é um ponto de sela, com a separatriz correspondente apresentando inclinação positiva. A figura 3, por sua vez, ilustra a situação em que o determinante é positivo, implicando que o valor absoluto da inclinação da isolinha $\hat{i}=0$ é menor que o da isolinha $\hat{V}=0$. Nesse caso, o equilíbrio será um nódulo instável. 
Figura 2

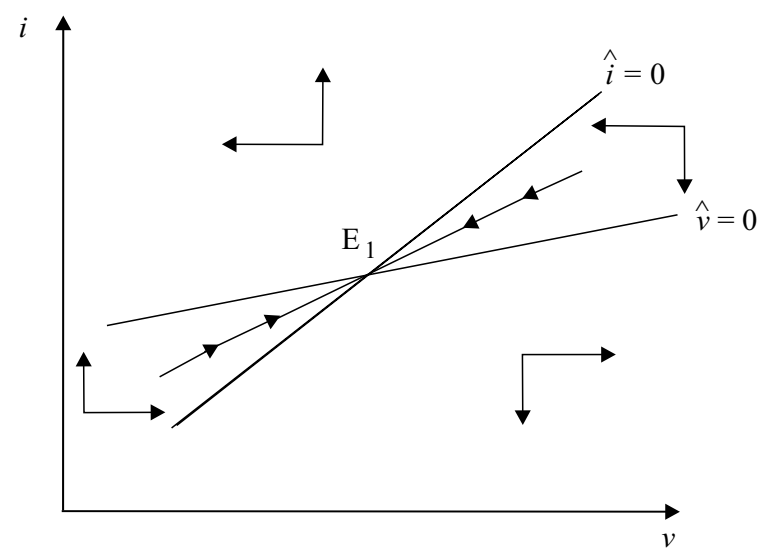

Figura 3

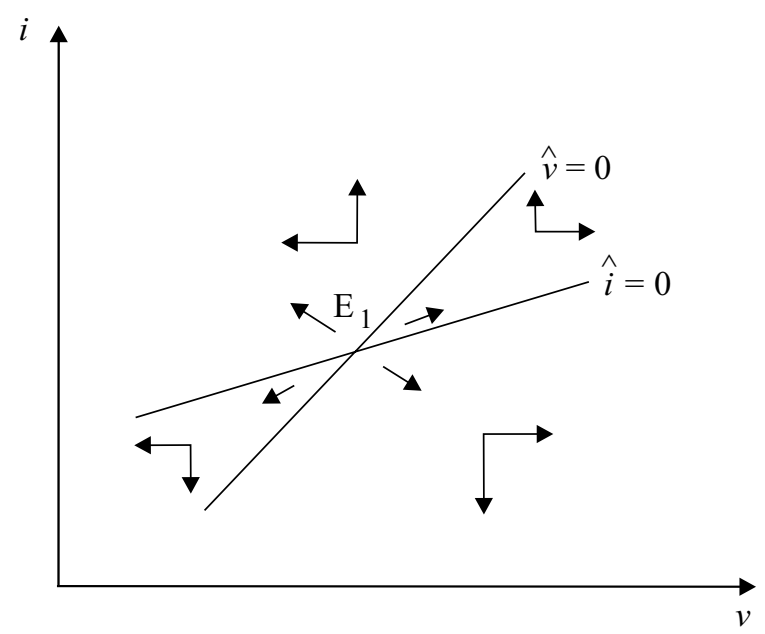




\subsection{Situação de plena utilização da capacidade}

Considerando-se que vigoram $u=u_{K}$ e $g^{d}>g$, as devidas substituições fazem com que o sistema descrito pelas eqs. (25) e (26) torne-se:

$$
\begin{aligned}
& \hat{V}=\mu\left(\epsilon_{0}+\epsilon_{1} u_{k}-V\right)-\theta_{1}^{\prime}\left(V-\varphi_{0}\right)-\theta_{2}^{\prime \prime}\left[\alpha_{0}-\left(s-\alpha_{1}\right)(1-V a) u_{k}\right]-\theta_{1}^{\prime \prime} i \\
& \hat{i}=\beta_{0}-\beta_{1}(1-V a) u_{k}+\phi\left[\alpha_{0}-\left(s-\alpha_{1}\right)(1-V a) u_{k}\right]-\phi^{\prime \prime} i+\phi^{\prime \prime}\left(V-\varphi_{0}\right)
\end{aligned}
$$

onde $g^{d}, r, g$ e $\hat{P}$ são dados por (3), (22), (23) e (24), respectivamente. As combinações paramétricas $\phi^{i}$ são dadas por:

$$
\begin{gathered}
\phi^{\prime}=\phi /\left(1-\theta_{2} \alpha_{2}\right)>0 \\
\phi^{\prime \prime}=\phi \alpha_{2}\left(1-\theta_{1} \varphi_{1}\right) /\left(1-\theta_{2} \alpha_{2}\right)>0 \\
\phi^{\prime \prime \prime}=\phi \alpha_{2} \theta_{1} /\left(1-\theta_{2} \alpha_{2}\right)>0
\end{gathered}
$$

onde os sinais correspondentes resultam das suposições anteriores $\theta_{1} \varphi_{1}<1$ e $\theta_{2} \alpha_{2}<1$.

A matriz Jacobiana associada a esse sistema dinâmico é a seguinte:

$$
\begin{gathered}
J_{11}^{+}=\partial \hat{V} / \partial V=-\mu-\theta_{1}^{\prime}-\theta_{2}^{\prime}\left(s-a_{\left.p h a_{1}\right) a u_{k}<0}\right. \\
J_{12}^{+}=\partial \hat{V} / \partial i=-\theta_{1}^{\prime \prime} \\
J_{21}^{+}=\partial \hat{i} / \partial V=\beta_{1} a u_{k}+\phi(s-\alpha) a u_{k}+\phi^{\prime \prime \prime}>0 \\
J_{22}^{+}=\partial \hat{i} / \partial i=-\phi^{\prime \prime}<0
\end{gathered}
$$

A eq. (29') mostra que um aumento no salário real provoca uma queda em sua taxa de variação devido a vários efeitos. Quando a plena ocupação da capacidade é alcançada, uma elevação no salário real não altera o equilíbrio de curto prazo da utilização da capacidade, o que mantém constante o salário real desejado pelos trabalhadores. Assim, um aumento no salário real reduz a taxa de variação do salário nominal. Ademais, um aumento no salário real, ao ampliar o hiato entre 
seu nível e aquele correspondente ao mark-up desejado das firmas, coloca uma pressão altista sobre a taxa de variação do preço. Por fim, um aumento no salário real gera uma queda na participação dos lucros na renda, uma intensificação no excesso de demanda (dado a maior propensão a poupar dos capitalistas) e uma pressão altista adicional sobre a taxa de variação proporcional do preço. E como detalhado na sequência da eq. (24), a assumida positividade das combinações $\theta_{1}^{\prime} \mathrm{e}$ $\theta_{2}^{\prime}$ significa que os dois últimos efeitos de um aumento no salário real efetivamente se traduzem num aumento da taxa de variação do preço.

O sinal da eq. (30') é ambíguo. Como mostra a eq. (22), o impacto de uma variação no juro nominal sobre o equilíbrio de curto prazo da taxa de lucro é nulo, como consequência da invariabilidade da utilização da capacidade. Entretanto, um dado aumento no juro nominal, ao elevar o mark-up desejado das firmas, aumenta a divergência entre o salário real efetivo e o implicado por aquele mark-up desejado, criando uma pressão altista sobre a taxa de inflação. Ademais, esse aumento nos juros nominais reduz diretamente a acumulação desejada, pois assumimos $\theta_{1} \varphi_{1}<$ 1, gerando uma pressão baixista sobre a taxa de inflação. Por fim, embora a taxa de inflação apareça recursivamente na função acumulação desejada participante de sua própria expressão, assumimos $\theta_{2} \alpha_{2}<1$. Assim, um aumento na taxa nominal de juros eleverá (reduzirá) a taxa de inflação quando $\theta_{1} \varphi_{1}>\theta_{2} \alpha_{2}\left(\theta_{1} \varphi_{1}<\theta_{2} \alpha_{2}\right)$.

A eq. (31') mostra que um aumento no salário real causa uma elevação na taxa de variação do juro nominal, sendo vários os efeitos em operação. Como mostra a eq. (22), esse aumento no salário real, ao reduzir a participação dos lucros na renda, reduz a taxa de lucro e, assim, eleva a taxa de variação do mark-up bancário. Ademais, a intensificação do excesso de demanda oriunda dessa redução da participação dos lucros na renda, pois a propensão a poupar dos capitalistas é maior, provoca uma elevação da taxa de variação proporcional da taxa de juros básica. Por outro lado, esse aumento no salário real, ao ampliar o hiato entre ele e o salário real implicado pelo mark-up desejado das firmas, pressiona positivamente a taxa de inflação e, como esta aparece recursivamente em sua própria expressão, intensifica ainda mais aquele excesso de demanda. Finalmente, a eq. (32') mostra que um aumento no juro nominal, ao elevar o mark-up desejado das firmas, reduz sua taxa de variação proporcional, dada a assumida positividade da combinação paramétrica $\phi^{\prime \prime}$.

Temos agora todos os elementos para uma análise qualitativa, baseada em diagramas de fase, das propriedades de estabilidade (local) do sistema quando a capacidade está sendo plenamente utilizada. Analisemos inicialmente a situação em que $J_{12}^{+}$é positivo, ou seja, $\theta_{1} \varphi_{1}<\theta_{2} \alpha_{2}$. Nesse caso, o traço da Jacobiana é negativo, satisfazendo assim uma condição necessária para a estabilidade da 
solução de equilíbrio. Caso seu determinante seja negativo (positivo), o equilíbrio será então do tipo ponto de sela (estável).

A figura 4 ilustra a situação em que o referido determinante é negativo, implicando que o valor absoluto da inclinação da isolinha $\hat{i}=0$ é maior que o da isolinha $\hat{V}=0$, algo que se segue de suas expressões algébricas. A inclinação da isolinha $\hat{V}=0$, dada por $-\left(J_{11} / J_{12}\right)$, é positiva. Uma vez que o sinal de $\partial \hat{V} / \partial i$ é positivo, $\hat{V}$ sobe conforme $i$ cresce, de maneira que seu sinal é positivo (negativo) à esquerda (direita) da correspondente isolinha, o que explica a direção das setas horizontais. A inclinação da isolinha $\hat{i}=0$, dada por $-\left(J_{21} / J_{22}\right)$, é igualmente positiva. Como o sinal de $\partial \hat{i} / \partial V$ é positivo, $\hat{i}$ cresce conforme $V$ sobe, de maneira que seu sinal é positivo (negativo) à direita (esquerda) da isolinha correspondente, o que explica a direção das setas verticais. Sendo assim, o equilíbrio de longo prazo, $E_{1}$, é um ponto de sela, com a separatriz correspondente apresentando uma inclinação negativa.

Figura 4

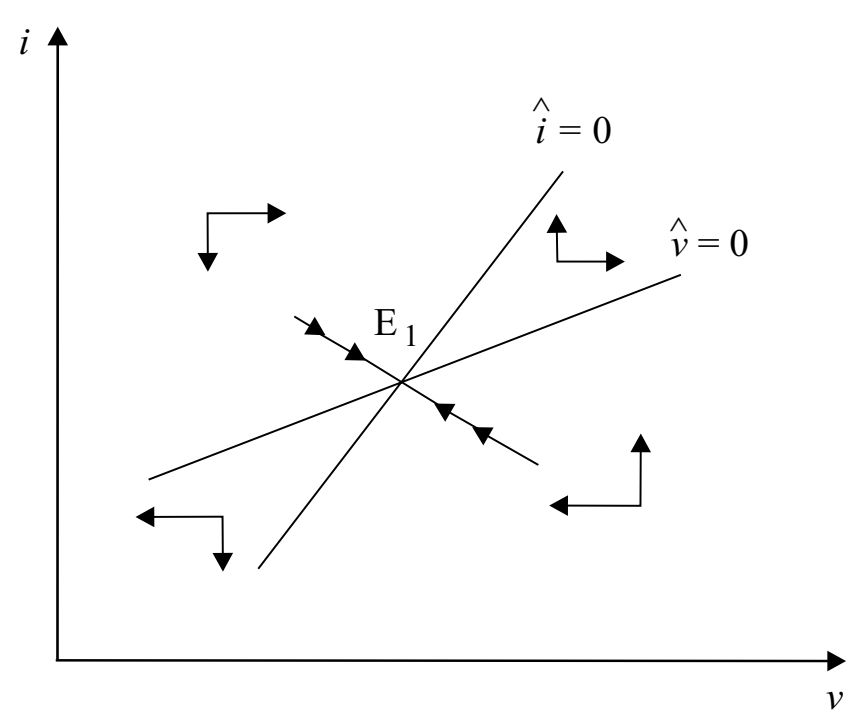

A figura 5 ilustra a situação de estabilidade, em que o valor absoluto da inclinação da isolinha $\hat{i}=0$ é menor que o da isolinha $\hat{V}=0$. A inclinação da isolinha $\hat{V}=0$, dada por $-\left(J_{11} / J_{12}\right)$, é positiva. Uma vez que o sinal de $\partial \hat{V} / \partial i$ é 
positivo, $\hat{V}$ sobe conforme $i$ cresce, de maneira que seu sinal é negativo (positivo) à direita (esquerda) da correspondente isolinha, o que explica a direção das setas horizontais. Por sua vez, a inclinação da isolinha $\hat{i}=0$, dada por $-\left(J_{21} / J_{22}\right)$, é igualmente positiva. Como o sinal de $\partial \hat{i} / \partial V$ é positivo, $\hat{i}$ sobe conforme $V$ sobe, seu sinal sendo positivo (negativo) à direita (esquerda) da isolinha correspondente, o que explica a direção das setas verticais. Sendo assim, o equilíbrio de longo prazo, $E_{1}$, é um nódulo estável.

Figura 5

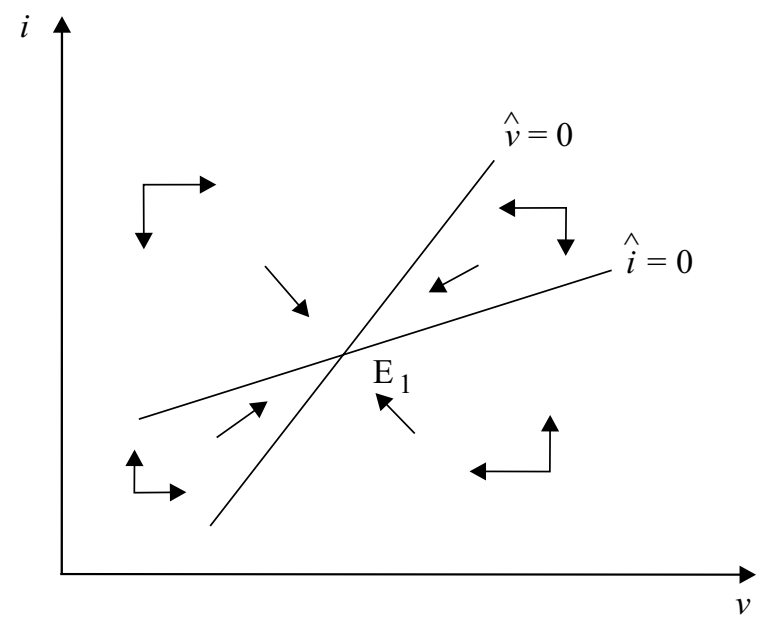

Analisemos agora a situação em que $J_{12}^{+}$é negativo, ou seja, $\theta_{1} \varphi_{1}>\theta_{2} \alpha_{2}$. O traço da Jacobiana é novamente negativo, enquanto que seu determinante é positivo, configurando a solução de equilíbrio estável ilustrada na figura 6 . A inclinação da isolinha $\hat{V}=0$, dada por $-\left(J_{11} / J_{12}\right)$, é negativa. Como o sinal de $\partial \hat{V} / \partial i$ é negativo, $\hat{V}$ cai conforme $i$ cresce, de maneira que seu sinal é negativo (positivo) à direita (esquerda) da correspondente isolinha, o que explica a direção das setas horizontais. Por sua vez, a inclinação da isolinha $\hat{i}=0$, dada por $-\left(J_{21} / J_{22}\right)$, é positiva. Como o sinal de $\partial \hat{i} / \partial V$ é positivo, $\hat{i}$ sobe conforme $V$ sobe, seu sinal sendo positivo (negativo) à direita (esquerda) da isolinha correspondente, daí a direção das setas verticais. Assim, o equilíbrio de longo prazo, $E_{1}$, é um foco estável. 
Gilberto Tadeu Lima, Antonio J. A. Meirelles

Figura 6

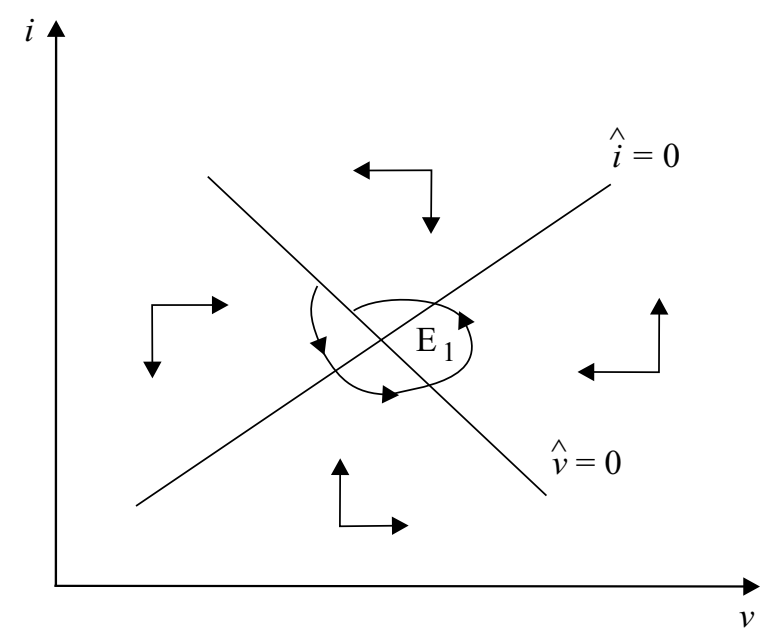

Deve-se ressaltar que a multiplicidade de possibilidades observada nesta subseção deriva da suposição de existência de excesso de demanda no mercado de bens, mesmo estando a economia operando a plena utilização da capacidade. Caso tivéssemos assumido a inexistência desse excesso, ou seja, $g^{d}=g$, o sistema dinâmico correspondente continuaria sendo descrito pelas eqs. (27) e (28). Agora, porém, a utilização da capacidade não seria dada pela eq. (15), mas por $u=u_{K}$, enquanto que a taxa de lucro seria dada pela eq. (22). Como pode ser facilmente checado, os sinais das derivadas parciais representadas nas eqs. (29)(32) seriam negativo, negativo, positivo e nulo, respectivamente. Uma vez que o determinante e o traço dessa matriz Jacobiana teriam sinais positivo e negativo, respectivamente, a solução de equilíbrio dinâmico correspondente seria um foco estável.

\subsection{Implicações de um mark-up bancário pró-cíclico}

Nas duas sub-seções anteriores, assumimos que um aumento na taxa de lucro sobre o capital físico, ao elevar a capacidade das firmas de servir suas obrigações financeiras, induzia uma redução no mark-up bancário. Suponhamos agora, porém, que a um aumento na taxa de lucro das firmas corresponda uma elevação no markup dos bancos, dado o intuito destes de apropriar uma parcela do excedente de 
renda daqueles que desejam obter empréstimos. ${ }^{15}$ Nos termos da eq. (10), isso significa que o parâmetro $\beta_{1}$ torna-se negativo.

Comecemos pela situação de excesso de capacidade. Embora a dinâmica da economia siga sendo descrita pelo sistema de equações diferenciais formado pelas eqs. (27) e (28), os sinais dos elementos da Jacobiana correspondente requerem revisão. O sinal de $\partial \hat{V} / \partial V$ continua ambíguo, enquanto que o sinal de $\partial \hat{V} / \partial i$ continua negativo, de acordo com as eqs. (29) e (30), respectivamente. Por seu turno, o sinal de $\partial \hat{i} / \partial V$ torna-se positivo. Agora, um aumento no salário real, ao acarretar uma elevação na taxa de lucro sobre o capital físico, eleva o markup dos bancos e, com isso, aumenta a taxa de variação proporcional da taxa de juros nominal. Finalmente, um aumento na taxa de juros nominal reduz a taxa de lucro sobre o capital físico, o mark-up dos bancos e, portanto, sua própria taxa de variação proporcional, de maneira que o sinal de $\partial \hat{i} / \partial i$ torna-se negativo.

Em relação ao caso original, onde, não obstante a ambigüidade no sinal de $\partial \hat{V} / \partial V$, a estabilidade estava descartada, o sistema tem agora na estabilidade uma possibilidade. Caso o sinal dessa derivada parcial seja negativo, o determinante e o traço da Jacobiana tornam-se positivo e negativo, respectivamente, resultando numa solução de equilíbrio estável. Portanto, um mark-up bancário pró-cíclico contribuirá para a geração de um equilíbrio estável caso um aumento no salário real, ao elevar a utilização da capacidade, aumente a taxa de variação proporcional do salário nominal numa proporção inferior ao aumento por ele provocado, ao elevar o hiato entre seu valor efetivo e aquele correspondente ao mark-up desejado das firmas, na taxa de variação proporcional do nível do preço. Caso, porém, o inverso ocorra, tornando positivo o sinal de $\partial \hat{V} / \partial V$, os sinais do determinante e do traço correspondentes tornam-se ambíguos.

Na situação de plena utilização da capacidade, com excesso de demanda, por sua vez, os sinais dos elementos da Jacobiana correspondente também devem ser revistos. O sinal de $\partial \hat{V} / \partial V$ continua negativo, enquanto que o sinal de $\partial \hat{V} / \partial i$ permanece ambíguo, conforme as eqs. (29') e (30'). Por seu turno, o sinal de $\partial \hat{i} / \partial V$ torna-se ambíguo. Como mostra a eq. (31'), um aumento no salário real, ao acarretar uma queda na taxa de lucro sobre o capital físico, agora reduz o mark-

\footnotetext{
${ }^{15}$ Outra rationale para essa suposição de que uma queda na taxa de lucro, ao reduzir a capacidade das firmas de servir obrigações financeiras, gera uma redução no mark-up bancário, pode ser buscada no estudo empírico de Brock e Rojas-Suarez (2000). Para uma amostra de países sul-americanos (Argentina, Bolívia, Chile, Colômbia e Peru), incluindo dados para meados da década de 90, apenas a Colômbia apresentou uma relação positiva entre índices de inadimplência e spreads bancários, com os demais apresentando uma relação negativa. Segundo os autores, essa evidência pode refletir o fato de que bancos com uma elevada proporção de empréstimos ruins, na tentativa de minorar os problemas daí oriundos, podem eventualmente reduzir seus spreads.
} 
up dos bancos e, com isso, provoca uma pressão baixista sobre a taxa de variação proporcional da taxa de juros nominal. Por outro lado, a intensificação do excesso de demanda oriunda dessa redução da participação dos lucros na renda, dado que a propensão a poupar dos capitalistas é maior, provoca uma elevação da taxa de variação proporcional da taxa de juros básica. Ademais, esse aumento no salário real, ao ampliar o hiato entre ele e o salário real relativo ao mark-up desejado das firmas, pressiona a taxa de inflação e, como esta aparece recursivamente em sua própria expressão, intensifica ainda mais aquele excesso de demanda. Por último, a eq. (32') mostra que $\partial \hat{i} / \partial i$ continua negativo.

Portanto, o sinal do traço da Jacobiana permanece negativo, embora a ambigüidade no sinal de $\partial \hat{i} / \partial V$ implique em maior ambigüidade no sinal de seu determinante. Caso o efeito via mark-up bancário pró-cíclico não seja suficientemente forte para gerar um sinal negativo para a derivada parcial $\partial \hat{i} / \partial V$, teremos então os mesmos casos ilustrados nas figuras (4), (5) e (6). Do contrário, abrem-se as seguintes possibilidades adicionais. Caso o sinal de $\partial \hat{V} / \partial i$ seja positivo, o sinal do determinante será necessariamente positivo e a solução de equilíbrio correspondente será um foco estável. Caso, por sua vez, o sinal de $\partial \hat{V} / \partial i$ seja negativo, o equilíbrio será um nódulo estável ou um ponto de sela, dependendo da inclinação relativa das isolinhas correspondentes. ${ }^{16}$

Quando o mark-up bancário e a taxa de lucro sobre o capital físico variam na mesma direção, podemos combinar as situações de excesso de capacidade e de plena utilização da maneira ilustrada pela figura 7. Quando a economia está operando com capacidade ociosa, um sinal negativo para $\partial \hat{V} / \partial V$ fará com que a solução de equilíbrio seja estável, conforme visto acima. Quando a capacidade produtiva está sendo plenamente utilizada, por sua vez, é possível a ocorrência de uma solução de equilíbrio ponto de sela como a ilustrada pela figura 4 , lembrando que esta também ilustra uma determinada possibilidade sob mark-up bancário pró-cíclico, conforme mencionado acima. Portanto, a economia teria duas soluções de equilíbrio de longo prazo, a saber, $E_{1}$, um equilíbrio localmente estável, e $E_{2}$, um ponto de sela, cuja separatriz correspondente teria inclinação negativa. Caso a economia estivesse acima dessa separatriz, sua dinâmica seria marcada por níveis crescentes de salário real e de juros nominais, podendo sua utilização da capacidade (eventualmente)

\footnotetext{
${ }^{16}$ Como visto ao final da sub-seção anterior, caso tivéssemos assumido a inexistência de excesso de demanda quando a capacidade produtiva está sendo plenamente utilizada, o sistema dinâmico correspondente continuaria sendo descrito pelas eqs. (27) e (28). Com a taxa de lucro sobre o capital físico e o mark-up bancário variando na mesma direção, porém, os sinais das derivadas parciais correspondentes seriam negativo, negativo, negativo e nulo, respectivamente. Dado que o sinal do determinante da Jacobiana seria negativo, a solução de equilíbrio dinâmico correspondente seria um ponto de sela.
} 
cair abaixo da plena e (eventualmente) convergir para aquela correspondente ao equilíbrio $E_{1}$. Caso, entretanto, a economia estivesse abaixo dessa separatriz, sua evolução ao longo do tempo seria marcada por níveis decrescentes de salário real e de juros nominais, mantendo a plena ocupação de sua capacidade produtiva.

Figura 7

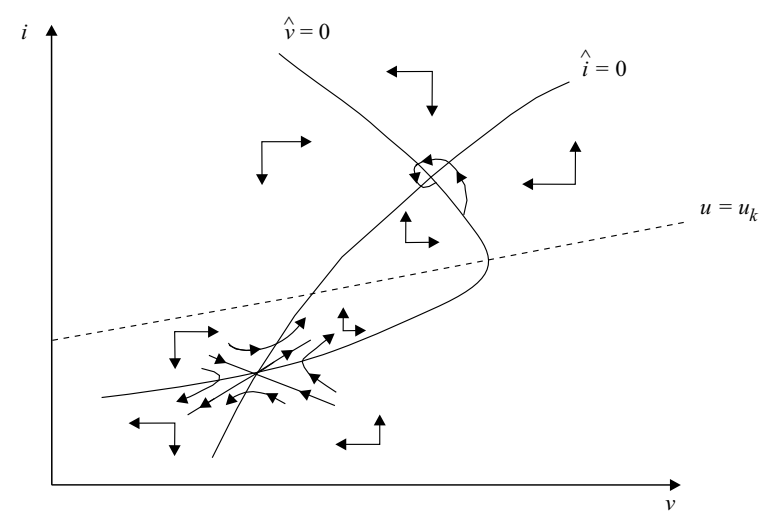

\section{Reprise e Considerações Finais}

O presente artigo elaborou um modelo macrodinâmico de utilização da capacidade produtiva, distribuição de renda e inflação por conflito, no qual a oferta de moeda de crédito é endógena, com a taxa de juros cobrada pela concessão de empréstimos sendo estabelecida pela aplicação de um mark-up sobre a taxa básica. Ao longo do tempo, a taxa de juros básica é alterada positivamente pela autoridade monetária sempre que um excesso de demanda no mercado de bens não é acomodável por uma variação na utilização da capacidade produtiva. O mark-up bancário, por sua vez, responde a variações na lucratividade das firmas. No caso anti-cíclico, um aumento na taxa de lucro sobre o capital físico, ao ampliar a capacidade das firmas de servir suas obrigações financeiras, reduz seu risco percebido de inadimplência e, com isso, promove uma redução no mark-up bancário. Na situação pró-cíclica, por seu turno, um aumento na taxa de lucro das firmas gera uma elevação no mark-up dos bancos, dado o intuito destes de se apropriar de uma maior fatia do excedente de renda daqueles que desejam obter empréstimos.

As decisões de produção das firmas são determinadas pelo nível de demanda efetiva, tendo sido analisadas as situações em que este é suficiente ou não para gerar 
a plena utilização da capacidade produtiva existente. O investimento desejado das firmas, por sua vez, depende positivamente da taxa de lucro sobre o capital físico e negativamente do juro real, enquanto a dinâmica da inflação é governada pelo conflito distributivo e, quando a capacidade produtiva encontra-se plenamente utilizada, também por eventuais excessos de demanda no mercado de bens. E como assumimos que esses excessos de demanda emergem a um dado nível do preço, o racionamento correspondente ocorre no investimento desejado e não no consumo.

Sob condições de excesso de capacidade produtiva, portanto, a necessária equalização ex-post entre o investimento desejado e a poupança é gerada através de variações na utilização da capacidade. Nessas condições, um aumento no salário real transfere renda dos capitalistas para os trabalhadores e, como a propensão a consumir destes é superior à daqueles, eleva a utilização da capacidade. Por outro lado, um aumento na taxa de juros nominal, ao se traduzir em um aumento em seu valor real, reduz o investimento desejado das firmas e, portanto, gera uma redução na utilização da capacidade. Além disso, um aumento no salário real, embora reduza a parcela dos lucros na renda, finda elevando mais que proporcionalmente a utilização da capacidade produtiva, gerando assim uma elevação na taxa de lucro sobre o capital físico. Por seu turno, um aumento na taxa de juros nominal, ao reduzir a utilização da capacidade, reduz a taxa de lucro das firmas.

Posto que, sob condições de capacidade ociosa, um aumento (redução) no salário real (juro nominal) gera uma elevação na utilização da capacidade instalada, é possível localizar no espaço salário-juro uma região em que a plena ocupação é alcançada. Nela, portanto, uma variação no salário real ou no juro nominal não altera a utilização da capacidade produtiva. No caso da taxa de lucro sobre o capital físico, porém, uma variação no salário real, ao gerar uma variação na participação dos lucros na renda, resulta numa variação na direção oposta da taxa de lucro sobre o capital físico, dado que a utilização da capacidade instalada deixou de desempenhar o papel acomodatício da situação de capacidade ociosa. O impacto imediato de uma variação na taxa de juros nominal sobre a taxa de lucro, por seu turno, finda sendo nulo, dada a invariabilidade da utilização da capacidade.

Com um comportamento anti-cíclico do mark-up bancário, por outro lado, o equilíbrio dinâmico do sistema formado pelas variáveis de estado salário real e taxa de juros nominal é necessariamente instável na situação de capacidade ociosa. Na situação de plena utilização da capacidade, esse comportamento do mark-up bancário assegura que o equilíbrio dinâmico seja necessariamente estável (quando não existe excesso de demanda) ou possa vir a ser estável (quando existe excesso 
de demanda). Um comportamento pró-cíclico do mark-up bancário, por seu turno, contribui para que se torne possível a estabilidade do equilíbrio dinâmico na situação de capacidade ociosa, além de manter a possibilidade de sua ocorrência na situação de excesso de demanda à plena ocupação da capacidade. Entretanto, esse comportamento pró-cíclico do mark-up bancário torna o equilíbrio dinâmico necessariamente instável na situação de inexistência de excesso de demanda à plena ocupação da capacidade produtiva. Por fim, a consideração de ambas as situações em nível de utilização da capacidade produtiva permitiu examinar qualitativamente uma possível configuração paramétrica conducente a um equilíbrio dinâmico duplo para as variáveis endógenas.

Em verdade, vários são os condicionantes do mark-up que os bancos aplicam sobre a taxa básica de captação. Como demonstrado neste artigo, um que pode ser incorporado, com certa facilidade, em um modelo dinâmico de determinação endógena do mark-up bancário, é a capacidade de pagamento das firmas e, portanto, o risco percebido de inadimplência que lhes é associado. Outros condicionantes igualmente relevantes, porém de complexidade superior, tais como a decisão de composição de portfólio e a preferência pela liquidez dos capitalistas financeiros e o regime de endividamento dos capitalistas produtivos, são objeto de pesquisa em curso pelos autores. ${ }^{17}$

\section{Referências}

Angbazo, L. (1997). Commercial bank net interest margins, default risk, interestrate risk, and off-balance sheet banking. Journal of Banking and Finance, 21.

Aronovich, S. (1994). Uma nota sobre os efeitos da inflação e do nível de atividade sobre o spread bancário. Revista Brasileira de Economia, 48(1).

Banco Central do Brasil (1999). Juros e spread bancário no Brasil. mimeo.

\footnotetext{
${ }^{17}$ Um modelo macrodinâmico pós-keynesiano de utilização e crescimento da capacidade produtiva, no qual a oferta de moeda de crédito é endógena e o endividamento das firmas é explicitamente formalizado, é elaborado em Meirelles e Lima (2001b). As firmas contraem empréstimos junto aos capitalistas financeiros para viabilizar seus planos de acumulação, de forma que seu grau de endividamento, expresso pela relação entre os estoques de dívida e de capital físico, varia intertemporalmente em função das taxas de investimento, de lucro sobre o capital físico e de juros. Com base nas variáveis de estado taxa de juros e grau de endividamento, desenvolve-se então uma análise qualitativa do comportamento macrodinâmico da economia, particularmente em nível de associação das propriedades de estabilidade de seu equilíbrio de longo prazo ao tipo de regime de financiamento - hedge, especulativo ou Ponzi - prevalecente no setor produtivo, conforme a sugestiva taxonomia elaborada por Minsky $(1975,1982)$.
} 
Brock, P. \& Rojas-Suarez, L. (2000). Understanding the behavior of bank spreads in Latin America. Journal of Development Economics, 63.

Cowling, K. (1982). Monopoly Capitalism. Macmillan, London.

Demirgüç-Kunt, A. \& Huizinga, H. (1999). Determinants of commercial bank interest margins and profitability: Some international evidence. The World Bank Economic Review, 13(2).

Dutt, A. K. (1989). Accumulation, distribution and inflation in a Marxian/PostKeynesian model with a rentier class. Review of Radical Political Economics, 21(3):18-26.

Dutt, A. K. (1990). Growth, Distribution and Uneven Development. Cambridge University Press, Cambridge.

Dutt, A. K. (1992). Rentiers in Post-Keynesian models. In Recent Developments in Post Keynesian Economics. P. Arestis \& V. Chick (Eds.). Aldershot: Edgard Elgar.

Dutt, A. K. (1994). On the long-run stability of capitalist economies: Implications of a model of growth and distribution. In New Directions in Analytical Political Economy. A. K. Dutt (Ed.). Aldershot: Edward Elgar.

Dutt, A. K. \& Amadeo, E. J. (1993). A Post-Keynesian theory of growth, interest and money. In The Dynamics of the Wealth of Nations; Growth, Distribution and Structural Change. M. Baranzini \& G. C. Harcourt (Eds.). St. Martins's Press, New York.

Kalecki, M. (1939-40). The supply curve of an industry under imperfect competition. Review of Economic Studies, 7.

Kalecki, M. (1971). Selected Essays on the Dynamics of the Capitalist Economy. Cambridge University Press, Cambridge.

Keynes, J. M. (1930). A treatise on money, vol. 2: The applied theory of money. In The Collected Writings of John Maynard Keynes. D. Moggridge (Ed.). Macmillan, London. Vol. VI.

Keynes, J. M. (1936). The General Theory of Employment, Interest and Money. Harcourt Brace, New York. 
Lavoie, M. (1996). Horizontalism, structuralism, liquidity preference and the principle of increasing risk. Scottish Journal of Political Economy, 43(3):275-300.

Lima, G. T. (1992). Em busca do tempo perdido: A recuperação pós-keynesiana da economia do emprego de Keynes. Rio de Janeiro: BNDES.

Lima, G. T. (1999). Progresso tecnológico endógeno, crescimento econômico e distribuição de renda. In Macroeconomia Moderna: Keynes e a Economia Contemporânea. G. T. Lima, J. Sicsú \& L. F. de Paula (Orgs.). Editora Campus, Rio de Janeiro.

Lima, G. T. (2000). Market concentration and technological innovation in a dynamic model of growth and distribution. Banca Nazionale del Lavoro Quarterly Review, LIII(215).

Meirelles, A. J. (1995). Moeda endógena e teoria monetária da produção. Revista de Economia Política, 15(3):18-30.

Meirelles, A. J. (1998). Moeda e Produção: Uma Análise da Polêmica PósKeynesiana Sobre a Endogenia Monetária. Mercado de Letras, Campinas, São Paulo: Fapesp.

Meirelles, A. J. \& Lima, G. T. (2001a). Regimes de endividamento, fragilidade financeira e dinâmica da atividade produtiva. Anais do $29^{\circ}$ Encontro Nacional de Economia da Anpec, Salvador, Dezembro.

Meirelles, A. J. \& Lima, G. T. (2001b). Taxa de juros, nível de atividade e distribuição: Um modelo dinâmico com mark-up bancário endógeno. Estudos Econômicos, 31(2):209-238.

Minsky, H. (1975). John Maynard Keynes. Columbia University Press, New York.

Minsky, H. (1982). Can "it" Happen Again? Essays on Instability and Finance. M. E. Sharpe, New York.

Moore, B. J. (1988). Horizontalists and Verticalists: The Macroeconomics of Credit Money. Cambridge University Press, Cambridge.

Rousseas, S. (1985). A markup theory of bank loan rates. Journal of Post Keynesian Economics, 8(1).

Rowthorn, B. (1981). Demand, real wages and economic growth. Thames Papers in Political Economy, Autumn. 
Saunders, A. \& Schumacher, L. (2000). The determinants of bank interest rate margins: An international study. Journal of International Money and Finance, 19.

Steindl, J. (1952). Maturity and Stagnation in American Capitalism. Monthly Review Press, New York.

Wong, K. P. (1997). On the determinants of bank interest margins under credit and interest rate risks. Journal of Banking and Finance, 21.

Wray, L. R. (1992). Commercial banks, the central bank, and endogenous money. Journal of Post Keynesian Economics, 14(3):297-310. 